\title{
Changes in Oxypurine Concentrations in Vitreous Humor of Pigs during Hypoxemia and Post-Mortem
}

\author{
JAN PETER POULSEN, TORLEIV OLE ROGNUM, STEPHANIE ØYASÆTER, AND \\ OLA DIDRIK SAUGSTAD \\ Institute for Surgical Research [J.P.P.], Institute of Forensic Medicine [T.O.R.], Institute for Pediatric Research \\ [S.Ø., O.D.S.], and Department of Pediatrics [O.D.S.], University of Oslo, The National Hospital, \\ N-0027 Oslo 1, Norway
}

\begin{abstract}
In the vitreous humor from three hypoxemic and one control group of pigs, hypoxanthine, xanthine, and uric acid concentrations were measured. The purine concentrations were measured before the hypoxemia, at the time of death, and $24 \mathrm{~h}$ post-mortem. During hypoxemia with arterial $\mathrm{O}_{2}$ tension between 2.1 and $3.0 \mathrm{kPa}$ [fractional inspired oxygen $\left(\mathrm{FiO}_{2}\right)=0.08$ ], hypoxanthine concentrations increased from a mean basal value of $11.7 \pm 5.6$ $\mu \mathrm{mol} / \mathrm{L}$ to $16.3 \pm 2.4 \mu \mathrm{mol} / \mathrm{L}$ at the time of death (NS). Xanthine concentrations changed from a basal value of 0.3 $\pm 0.1 \mu \mathrm{mol} / \mathrm{L}$ to $0.6 \pm 0.2 \mu \mathrm{mol} / \mathrm{L}(p<0.02)$, and uric acid changed from $3.4 \pm 1.1 \mu \mathrm{mol} / \mathrm{L}$ to $5.0 \pm 4.5 \mu \mathrm{mol} / \mathrm{L}$ (NS). During hypoxemia with arterial $\mathrm{O}_{2}$ tension between 3.0 and $4.0 \mathrm{kPa}\left(\mathrm{FiO}_{2}=0.11\right)$, hypoxanthine increased in the vitreous humor from a mean basal value of $9.1 \mu \mathrm{mol} / \mathrm{L}$ to $20.3 \mu \mathrm{mol} / \mathrm{L}$ at the time of death $(p<0.02)$. Xanthine concentrations increased from $0.3 \mu \mathrm{mol} / \mathrm{L}$ to $1.3 \mu \mathrm{mol} / \mathrm{L}$ $(p<0.05)$, whereas there was no change in uric acid concentration (basal $5.0 \pm 0.8 \mu \mathrm{mol} / \mathrm{L}$ and final $4.5 \pm 1.0$ $\mu \mathrm{mol} / \mathrm{L}$ ). During milder hypoxemia with arterial $\mathrm{O}_{2}$ tension between 4.3 and $5.6 \mathrm{kPa}\left(\mathrm{FiO}_{2}=\mathbf{0 . 1 4}\right)$, or in the control group $\left(\mathrm{FiO}_{2}=0.21\right)$, neither of the metabolites changed significantly. The vitreous humor was not stable postmortem, inasmuch as the mean concentration of hypoxanthine increased from $18.2 \pm 7.7 \mu \mathrm{mol} / \mathrm{L}$ to $121.6 \pm 57.4$ $\mu \mathrm{mol} / \mathrm{L} 24 \mathrm{~h}$ post-mortem $(p<0.01)$. In the same period, xanthine increased from a mean $0.9 \pm 0.6 \mu \mathrm{mol} / \mathrm{L}$ to a mean $4.9 \pm 5.2 \mu \mathrm{mol} / \mathrm{L}(p<0.01)$. (Pediatr Res $28: 482$ $484,1990)$
\end{abstract}

\section{Abbreviations}

SIDS, sudden infant death syndrome

CSF, cerebrospinal fluid

$\mathrm{PaO}_{2}$, arterial $\mathrm{O}_{2}$ tension

$\mathrm{FiO}_{2}$, fractional inspired oxygen

The etiology and pathogenesis of SIDS is still unknown. Some authors claim that SIDS might be due to an acute process, such as cardiac arrhythmia (1), whereas others find evidence of a more

Received January 15, 1990; accepted June 5, 1990.

Correspondence and reprint requests: Dr. Jan Peter Poulsen, Institute for Surgical Research, University of Oslo, The National Hospital, N-0027 Oslo 1, Norway.

Supported by the Norwegian Women's Public Health Association, the Norwegian Research Council for Science and the Humanities, the Lærdal Foundation for Acute Medicine. Odd Fellow Medical Research Foundation, and the Norwegian SIDS Parents Association. J.P.P. is a Research Fellow with The Norwegian Cancer Society. prolonged disease process, which may include long-standing hypoxia $(2,3)$. During tissue hypoxia, elevated hypoxanthine levels have been found in plasma (4-6), $\operatorname{CSF}(7,8)$, and urine (9). We have also measured the hypoxanthine levels in vitreous humor post-mortem, and documented high levels when death was preceded by respiratory failure and hypoxemia $(10,11)$. Recently, we reported high levels of hypoxanthine in the vitreous humor of victims of SIDS (12), and therefore concluded that hypoxemia precedes death in SIDS.

In our present study, we report how three degrees of hypoxemia in young pigs influence the level of hypoxanthine, xanthine, and uric acid in the vitreous humor. Furthermore, we investigated the time factor involved in hypoxanthine accumulation in the vitreous humor during hypoxemia. We also report how hypoxanthine concentrations in the vitreous humor change during the first $24 \mathrm{~h}$ post-mortem. We found this important, inasmuch as the time from death to sample collection could have influenced the concentrations of hypoxanthine in the vitreous humor that we have reported from our SIDS cases.

\section{MATERIALS AND METHODS}

Approval. The local hospital's ethical committee for animal studies approved these experiments.

Animal model. The animal model was similar to that previously described (13). Twenty-two young pigs of either sex (the males had been castrated shortly after birth) weighing $17-22 \mathrm{~kg}$ (mean $18.1 \mathrm{~kg}$ ) were used. They were anesthetized with an intraperitoneal injection of sodium pentobarbital $(30 \mathrm{mg} / \mathrm{kg})$. An i.v. line was established through an ear vein, and a continuous infusion of Ringer acetate $(10 \mathrm{~mL} / \mathrm{kg} / \mathrm{h})$ was given during the experiment. A further $100 \mathrm{mg}$ of sodium pentobarbital was given i.v. if necessary every $30 \mathrm{~min}$. A cuffed tube was placed in the trachea via a tracheostomy. Artificial ventilation was given by a ventilator (Servo-ventilator 900B, Elema-Schønander, Stockholm, Sweden). Ventilation rate and tidal volume were adjusted until arterial $\mathrm{CO}_{2}$ tension ranged between 4 and $5.3 \mathrm{kPa}(30-40$ $\mathrm{mm} \mathrm{Hg}$ ). No further adjustments of the ventilator were done during the hypoxemic period.

Polyethylene catheters were inserted into a femoral artery and a femoral vein. The arterial catheter was used for measuring blood gases. The venous catheter was used for giving Ringer acetate plus additional sodium pentobarbital.

After surgery, the pigs were left for a stabilizing period of at least $1 \mathrm{~h}$ before basal concentrations were measured, and then divided into three hypoxemic and one control group. Seven animals were made hypoxemic by artificial ventilation with $8 \%$ oxygen in nitrogen $\left(\mathrm{FiO}_{2}=0.08\right)$ (group 1). Seven animals were ventilated with $11 \%$ oxygen $\left(\mathrm{FiO}_{2}=0.11\right)$ (group 2$)$. Five animals were ventilated with $14 \%$ oxygen $\left(\mathrm{FiO}_{2}=0.14\right)$ (group 3 ), and 
three animals were ventilated with room air $\left(\mathrm{FiO}_{2}=0.21\right)$, serving as normoxemic controls (group 4). The oxygen concentrations were measured continuously in all pigs during the experiments with a Dameca OM 831 oxygen monitor (Dameca Inc., Copenhagen, Denmark).

During hypoxemia with $\mathrm{FiO}_{2}=0.08$, the $\mathrm{PaO}_{2}$ remained between 2.1 and $3.0 \mathrm{kPa}(15.8-22.5 \mathrm{~mm} \mathrm{Hg})$. This degree of hypoxemia lasted until the animals died after a mean of 170 min (range 120-240 min). During hypoxemia with $\mathrm{FiO}_{2}=0.11$, the $\mathrm{PaO}_{2}$ remained between 3.0 and $4.0 \mathrm{kPa}(22.5-30 \mathrm{~mm} \mathrm{Hg})$, and these pigs died after a mean of $283 \mathrm{~min}$ (range $165-445 \mathrm{~min}$ ). During the mildest hypoxemia $\left(\mathrm{FiO}_{2}=0.14\right)$, the $\mathrm{PaO}_{2}$ remained between 4.3 and $5.6 \mathrm{kPa}(32.5-42 \mathrm{~mm} \mathrm{Hg})$. All animals tolerated this degree of hypoxemia for $480 \mathrm{~min}$, after which they were killed with an i.v. overdose of sodium pentobarbital. The pigs in the control group were observed from 185 to $480 \mathrm{~min}$ and then killed. During artificial ventilation, $1 \mathrm{~mL}$ of pancuronium bromide (Pavulon $2 \mathrm{mg} / \mathrm{mL}$, Organon Teknika, Boxtel, Netherlands) was given i.v. every $30 \mathrm{~min}$ to prevent muscular contractions, which may lead to artificially high hypoxanthine levels (14).

Blood samples. Arterial blood gases were measured with an AVL 945 Automatic Blood Gas System (AVL Biomedical Instruments, Schaffhausen, Switzerland) before hypoxemia, during hypoxemia at 5,15 , and $30 \mathrm{~min}$, and then every $30 \mathrm{~min}$ as long as the experiment lasted. The withdrawn blood was immediately replaced with an equal volume of sterile $\mathrm{NaCl}(0.9 \%)$.

Sampling of vitreous humor. In the pig's right eye, the conjunctiva was dissected free from the sclera. Any bleeding was stopped by microcoagulation (Concept Cauterette I, Concept Inc., Clearwater, FL). The vitreous humor was sampled twice with a vacutainer through a puncture of the sclera about $6 \mathrm{~mm}$ posterior to the corneal limbus. Two hundred to $400 \mu \mathrm{L}$ of fluid were taken at each sampling. The two sampling times were before start of the hypoxemia and just after death. Multiple sampling during the hypoxemia was tried, but this procedure led to artificially high values of hypoxanthine compared with control values from the left eye (see below) and the procedure had to be abandoned (results not shown).

Within $5 \mathrm{~min}$ of the animal's death, a similar procedure was done in the left eye to obtain a control sample of vitreous humor. In case of a difference in the hypoxanthine concentration in the two eyes at the time of death, the value from the unpunctured (left) eye was accepted. In some animals, the left eye was then enucleated, put in a glass jar and stored at $4^{\circ} \mathrm{C}$. Twenty-four $\mathrm{h}$ post-mortem, a second sample from the vitreous humor of this eye was taken for analysis of hypoxanthine and xanthine.

The samples of vitreous humor were immediately centrifuged for $10 \mathrm{~min}$ at $1800 \times \mathrm{g}, 4^{\circ} \mathrm{C}$ to remove cells or other contaminating particles (pigmented pieces of retina). The clear vitreous humor was transferred into polypropylene tubes and frozen at $-20^{\circ} \mathrm{C}$ until the time of analysis.

Analysis of hypoxanthine, xanthine, and uric acid concentrations. The hypoxanthine and xanthine levels in vitreous humor were analyzed using an HPLC method $(15,16)$.

The sample of vitreous humor had to be diluted before filtration at least three times with the mobile phase $\left(0.005 \mathrm{M} \mathrm{KH}_{2} \mathrm{PO}_{4}\right.$, $\mathrm{pH}$ 5.7). Using a syringe, the vitreous humor was passed through a 4-mm Millex- $\mathrm{HV}_{4}$ unit with $0.45-\mu \mathrm{m}$ pore size (Millipore Corp., Bedford, MA).

The chromatography, identification, and quantification of the peaks in the HPLC effluents were done as previously described (13). All pure standards used for the HPLC were obtained from Sigma Chemical Co., St. Louis, MO.

Uric acid was measured on an RA-1000 (Technicon Instruments, Tarrytown, NY) automatic blood analyzer.

Statistics. Mean values \pm SD are given. Wilcoxon's two-tailed rank test was applied for testing the significance of differences between comparable groups. A $p$ value $<0.05$ was considered statistically significant.

\section{RESULTS}

Hypoxanthine, xanthine, and uric acid in the vitreous humor. The concentrations of hypoxanthine in the vitreous humor of the four groups are given in Figure 1. The mean concentration before the start of hypoxemia was $10.3 \pm 4.0 \mu \mathrm{mol} / \mathrm{L}$, with no statistical difference between the groups. In group 1, the concentrations increased only slightly up to the time of death [final level $16.3 \pm 2.4 \mu \mathrm{mol} / \mathrm{L}(\mathrm{NS})$ ], giving an average change per hour hypoxemia of $1.7 \pm 2.9 \mu \mathrm{mol} / \mathrm{L} / \mathrm{h}$ (NS). However, in group 2 , the concentration of hypoxanthine in the vitreous humor increased up to the time of death in all the pigs, with a mean augmentation of $12.0 \pm 7.9 \mu \mathrm{mol} / \mathrm{L},(p<0.02)$ and an average rate of change of $3.4 \pm 3.3 \mu \mathrm{mol} / \mathrm{L} / \mathrm{h}(p<0.02)$.

In the mildest hypoxemic pigs, group 3 , the increase in the concentration of hypoxanthine in the vitreous humor $(4.6 \pm 7.3$ $\mu \mathrm{mol} / \mathrm{L})$ was not significant. The average rate of change per hour of hypoxemia $(0.6 \pm 0.9 \mu \mathrm{mol} / \mathrm{L} / \mathrm{h})$ was significantly lower than that in group $2(p<0.02)$. There were no changes in the concentration of hypoxanthine in the vitreous humor in the control group.

The mean xanthine concentration in the vitreous humor in the pigs was $0.3 \pm 0.1 \mu \mathrm{mol} / \mathrm{L}$ before hypoxemia. In group 1 , it increased to $0.6 \pm 0.2 \mu \mathrm{mol} / \mathrm{L}(p<0.02)$, and in group 2 it increased to $1.3 \pm 0.7 \mu \mathrm{mol} / \mathrm{L}(p<0.05)$, whereas in the two other groups there was no significant increase.

The mean uric acid concentration in the vitreous humor of pigs in groups 1 and 2 was $4.1 \pm 1.3 \mu \mathrm{mol} / \mathrm{L}$ before hypoxemia. There was no change in uric acid after hypoxemia; in group 1, the final concentration was $5.0 \pm 4.5 \mu \mathrm{mol} / \mathrm{L}$ (NS), and in group 2 the final concentration was $4.5 \pm 1.0 \mu \mathrm{mol} / \mathrm{L}$ (NS). Uric acid was not measured in the two other groups.

Eleven randomly selected left eyes from all four groups of pigs were enucleated shortly after death and stored at $4^{\circ} \mathrm{C}$, and a second sample of vitreous humor was collected from these eyes $24 \mathrm{~h}$ later. Figure 2 shows that the concentration of hypoxanthine in these eyes changed from a mean of $18.2 \pm 7.7 \mu \mathrm{mol} / \mathrm{L}$ at the time of death to a mean of $121.6 \pm 57.4 \mu \mathrm{mol} / \mathrm{L}$ at $24 \mathrm{~h}$ after death $(p<0.01)$. The average rate of change in hypoxanthine concentration in the vitreous humor of pigs post-mortem at $4^{\circ} \mathrm{C}$ was $4.3 \pm 2.3 \mu \mathrm{mol} / \mathrm{L} / \mathrm{h}$. The postmortem change was independent on the degree of hypoxemia before death.

The concentration of xanthine in these eyes changed from a mean of $0.9 \pm 0.6 \mu \mathrm{mol} / \mathrm{L}$ at the time of death to a mean of 4.9 $\pm 5.2 \mu \mathrm{mol} / \mathrm{L}$ at $24 \mathrm{~h}$ after death $(p<0.01)$.

Uric acid was not measured at $24 \mathrm{~h}$ post-mortem.

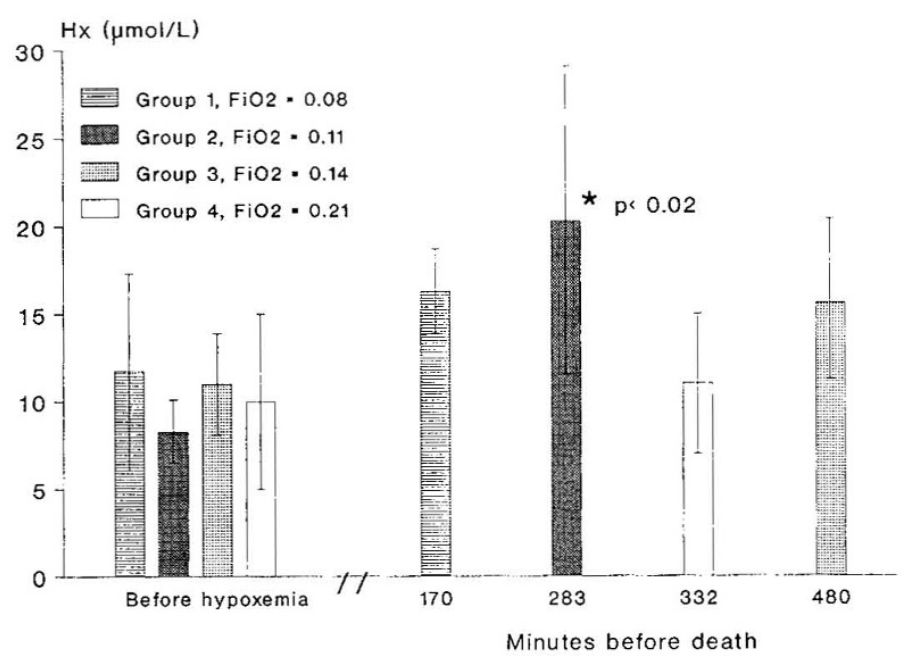

Fig. 1. Hypoxanthine $(H x)$ concentrations $(\mu \mathrm{mol} / \mathrm{L})$ in the vitreous humor before the start of hypoxemia and at the time of death in four groups of pigs. Mean time until death varied in the four groups. Mean values $\pm \mathrm{SD}$ are given. ${ }^{*} p<0.02$ compared with values before hypoxemia. 


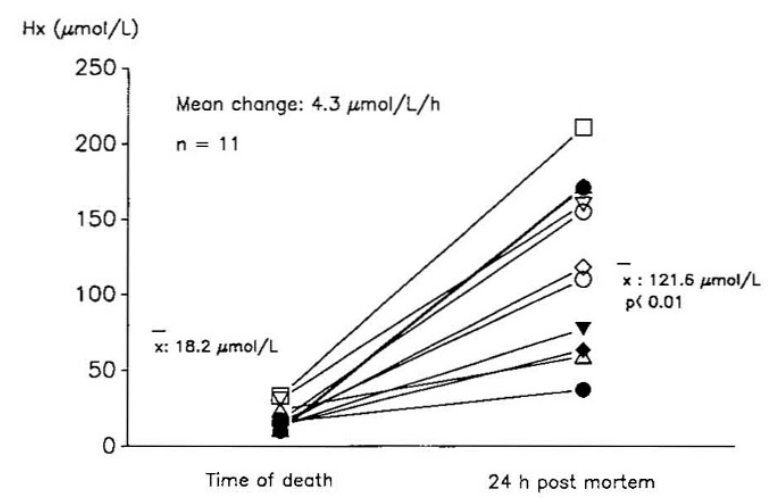

Fig. 2. Hypoxanthine $(H x)$ concentrations $(\mu \mathrm{mol} / \mathrm{L})$ in the vitreous humor at the time of death and $24 \mathrm{~h}$ post-mortem in 11 eyes randomly selected from pigs from all four groups of hypoxemia. Storage temperature was $4^{\circ} \mathrm{C}$.

\section{DISCUSSION}

Vitreous humor is easily sampled post-mortem and is considered to be relatively free from contamination by blood, bacteria, and products of postmortem autolysis. During life, however, vitreous humor is difficult to obtain, and to our knowledge, the biochemical changes occurring before and after death in the same individuals have not previously been studied.

In an earlier report on postmortem hypoxanthine levels in the vitreous humor (10), we assumed that values found in cases of sudden death reflected the levels in vivo, ranging between 0 and $540 \mu \mathrm{mol} / \mathrm{L}$, with a mean 10 to 20 times higher than in plasma. Our present results show that this assumption was wrong, as the vitreous humor of pigs was found to have a basal concentration of hypoxanthine even below that found in plasma or CSF (13). Our present findings correspond well with the data recently published by Gardiner et al. (17).

Subjecting our pigs to severe hypoxemia $\left(\mathrm{FiO}_{2}=0.08\right)$ did not lead to any significant increase in vitreous humor hypoxanthine. However, subjecting the animals to a milder degree of hypoxemia $\left(\mathrm{FiO}_{2}=0.11\right)$ increased the mean vitreous humor hypoxanthine concentration about 2.5 -fold. The duration of the hypoxemia in group 2 was, however, much longer (283 versus $170 \mathrm{~min}$ in group 1). These results suggest, therefore, that for reaching high concentrations of hypoxanthine in the vitreous humor, the length of the hypoxemic period may be as or perhaps more important than the degree of hypoxemia. Our present experiment supports our belief that longstanding hypoxemia is necessary to raise the hypoxanthine levels in the vitreous humor up to the values found in SIDS cases or in children dying of respiratory distress syndrome $(11,12)$.

Whether hypoxanthine and xanthine are formed locally in the tissues of the eye during hypoxemia or they diffuse passively into the vitreous humor from the CSF or plasma, we do not know. In these pigs, no relationship was found between the concentrations in the vitreous humor and concentrations measured in CSF or plasma (13), except that a lower concentration was always found in the vitreous humor than in the other two extracellular body fluids.

However, previous studies on uric acid concentrations in monkeys and rats (18-20) indicate that the concentration of uric acid in the aqueous humor and in the retina depends on local synthesis, rather than on a systemic increase in the concentration. Our findings of no change in uric acid concentrations in the vitreous humor after hypoxemia indicate that under these conditions no uric acid is formed. This could only mean that the enzyme xanthine oxidase (EC 1.1.3.22) is not present in the eye or vitreous humor in any significant concentration.

The vitreous humor hypoxanthine concentrations are not stable post-mortem. We have recently measured human vitreous humor hypoxanthine serially post-mortem (Rognum TO, Poulsen JP, Hauge S, Øyasæter S, Saugstad OD, unpublished data). When the bodies were stored at $6^{\circ} \mathrm{C}$, there was an average increase of $3.5-4.0 \mu \mathrm{mol} / \mathrm{L} / \mathrm{h}$. This change corresponds well with the increase of $4.3 \mu \mathrm{mol} / \mathrm{L} / \mathrm{h}$ post-mortem in pigs reported in this paper, but is considerably lower than the findings recently reported by Gardiner et al. (17). He found an hourly postmortem increase in pigs of about $13 \mu \mathrm{mol} / \mathrm{L}$, but his storage temperature was $20^{\circ} \mathrm{C}$. Gardiner's data thus indicate that hypoxanthine concentration increases faster in the vitreous humor with higher surrounding temperature.

Whether the enucleation of the eyes, or the fact that these eyes had been punctured once at the time of death, influences the concentration measured $24 \mathrm{~h}$ post-mortem is not known.

In summary, postmortem vitreous humor hypoxanthine concentrations may reflect the duration of hypoxemia before death better than the degree of hypoxemia. Further, this may also be true in human newborns where no significant increase in vitreous humor hypoxanthine was found unless the baby had suffered from at least 4 to $5 \mathrm{~h}$ hypoxemia before death (11).

Acknowledgment. The authors thank the Department of Clinical Chemistry at The National Hospital for performing the uric acid analyses.

\section{REFERENCES}

1. Southhall DP, Richards JM, de Swiet M 1983 Identification of infants destined to die unexpectedly during infancy: evaluation of predictive importance of prolonged apnoea and disorders of cardiac rhythm of conduction. $\mathrm{Br}$ Med $\mathrm{J}$ [Clin Res] 286:1092-1096

2. Becker LE 1983 Neuropathological basis for respiratory dysfunction in sudden infant death syndrome. In: Tildon JT, Roeder LM, Steinschneider A (eds) Sudden Infant Death Syndrome. Academic Press, New York, pp 99-114

3. Valdes Dapena M 1986 Sudden infant death syndrome: morphology update for forensic pathologists-1985. Forensic Sci Int 30:177-186

4. Saugstad OD 1975 Hypoxanthine as a measurement of hypoxia. Pediatr Res 9:158-161

5. Thiringer K 1983 Cord plasma hypoxanthine as a measure of fetal hypoxia. Acta Paediatr Scand 72:231-237

6. Pietz J, Guttenberg N. Gluck I 1988 Hypoxanthine: a marker for asphyxia. Obstet Gynecol 72:762-766

7. Meberg A. Saugstad OD 1978 Hypoxanthine in cerebrospinal fluid in children. Scand J Clin Lab Invest 38:437-440

8. Manzke H, Staemmler W 1981 Oxypurine concentrations in CSF in children with different diseases of the nervous system. Neuropediatrics 12:209-214

9. Manzke H. Dörner K. Grünitz J 1977 Urinary hypoxanthine, xanthine, and uric acid in newborn infants with perinatal complications. Acta Paediatr Scand 66:713-717

10. Saugstad OD, Olaisen B 1978 Post-mortem hypoxanthine levels in the vitreous humor. An introductory report. Forensic Sci int 12:33-36

11. Saugstad OD. Rognum TO 1988 High postmortem levels of hypoxanthine in the vitreous humor of premature babies with respiratory distress syndrome. Pediatrics 81:395-398

12. Rognum TO. Saugstad OD. Øvasæter S. Olaisen B 1988 Elevated levels of hypoxanthine in the vitreous humor indicate prolonged cerebral hypoxia in victims of sudden infant death syndrome. Pediatrics 82:615-618

13. Poulsen JP, Øyasæter S, Sanderud J, Rognum TO, Saugstad OD 1990 Hypoxanthine, xanthine and uric acid concentrations in the cerebrospinal fluid, plasma and urine in hypoxemic pigs. Pediatr Res 28:477-481

14. Harkness RA 1988 Hypoxanthine, xanthine and uridine in body fluids, indicators of ATP depletion. J Chromatogr 429:255-278

15. Wung WE, Howell SB 1980 Simultaneous liquid chromatography of 5-fluorouracil, uridine, hypoxanthine, xanthine. uric acid, allopurinol and oxypurinol in plasma. Clin Chem 26:1704-1708

16. Simmonds RJ. Harkness RA 1981 High-performance liquid chromatographic methods for base and nucleoside analysis in extracellular fluids and in cells. J Chromatogr 226:369-381

17. Gardiner EE, Newberry RC. Keng J-Y 1989 Postmortem time and storage temperature affects the concentrations of hypoxanthine, other purines, pyrimidines, and nucleosides in avian and procine vitreous humor. Pediatr Res 26:639-642

18. Lam K, Liu K, Yee R, Lee P 1983 Detection of uric acid in aqueous humor by high pressure liquid chromatography. Curr Eye Res 2:645-649

19. Bonney CH, Lam K. Fong D 1988 Integrity of the blood-aqueous barrier in hyperuricemia. Ann Ophthalmol 20:140-142

20. Iriyama K, Yoshiura M, Iwamoto T, Kamada Y. Nozawa H. Mizuno A, Matsuzaki H 1986 Liquid chromatographic determination of uric acid and ascorbic acid in rat retinae after ophthalmic artery and optic nerve ligation. Curr Eye Res 5:479-483 